\title{
Enhanced Mathematical Modelling of Interior Permanent Magnet Synchronous Machine Considering Saturation, Cross-Coupling and Spatial Harmonics effects
}

\author{
Armin Dietz \\ Technische Hochschule Nürnberg \\ Institut ELSYS \\ 90489 Nuremberg, Germany \\ Email: armin.dietz@th-nuernberg.de
}

\author{
M. Caruso, A. O. Di Tommaso, R. Miceli, \\ Member IEEE, and C. Nevoloso \\ Department of Engineering \\ University of Palermo \\ Viale delle Scienze, Building nr. 9, 90128 Palermo, Italy \\ Email: massimo.caruso16@unipa.it \\ antoninooscar.ditommaso@unipa.it \\ rosario.miceli@unipa.it \\ claudio.nevoloso@unipa.it
}

\begin{abstract}
The Interior Permanent Magnet Synchronous machine (IPMSM) conventional mathematical model is generally employed to investigate and simulate the IPMSM control and drive system behaviour. However, magnetic nonlinearities and spatial harmonics have a substantial influence on the IPMSM electromagnetic behaviour and performances. In order to simulate the IPMSM real electromagnetic behaviour, this paper describes an enhanced mathematical model that takes into account the saturation, cross-coupling and spatial harmonics effects. This model has been implemented in Matlab ${ }^{\circledR} /$ Simulink environment where the electric and magnetic parameters are derived from FEA investigations and implemented by the use of lookup tables. The high fidelity of the proposed IPMSM Simulink model is validated by the results of the FEA investigations carried out.
\end{abstract}

Keywords_Finite element analysis (FEA); interior permanent magnet synchronous machine (IPMSM); saturation; cross-coupling; spatial harmonics.

\section{INTRODUCTION}

In the last decade, it has been detected an increasing trend in the automotive [1]-[2] aerospace [3]-[4] and marine industry [5]-[6] of the adoption of IPMSMs drives due to their peculiarity features, such as high power factor, high torque density and high efficiency. In order to obtain electric drives with high performances, particular attention is addressed to the design of innovative control algorithm for IPMSM a [7]-[11]. Therefore, in order to evaluate the effectiveness and the performances of electrical machine control algorithms, during the design phase, the simulation study represents a fundamental phase. For this purpose, the IPMSM conventional mathematical model is commonly used. This model is based on idealized hypotheses that involves in the absence of self-saturation, cross-coupling, iron core losses, temperature effects and spatial harmonics in phase voltages. However, nonlinearity and temperature effects have a substantial impact on the IPMSM performances. The conventional IPMSM mathematical model in $d q$ reference frame may be unreliable in predicting the performances of saturated machines [12]-[14]. The parameters of the $d q$-axes model vary nonlinearly, depending on the operating conditions that change the level of saturation and magnetic field distribution in the motor. The self and cross magnetic saturation have a substantial influence on the $d q$-axes inductances. In addition, the anisotropy magnetic behaviour of IPMSMs not only determines a nonlinear relationship between the electromagnetic torque and the stator current components due the presence of reluctance torque, but also generates to greater level of spatial harmonics in phase voltages due to the inherently large variation in the magnetic energy with the rotor position [15]. Since traction motors for automotive applications are designed to work in the field weakening region and they operate in highly nonlinear conditions, a high fidelity IPMSM model can be of great aid for the design of innovative control strategies and for the evaluation of their performances.

This paper proposes an enhanced mathematical model of the IPMSM that take into account simultaneously the magnetic saturation, cross-coupling and spatial harmonics effects. The paper is structured as follows: Section II describes the conventional IPMSM mathematical model, Section III describes the proposed enhanced IPMSM mathematical model, Section IV the characterization of IPMSM under study in FE environment and Section V the 
implementation of the mentioned enhanced mathematical model in Simulink environment and its validation.

\section{IPMSM CONVENTIONAL MATHEMATICAL MODEL}

The conventional approach to modelling the IPMSM is based on the following voltage, flux and torque equations:

$$
\begin{aligned}
& v_{d}(t)=R i_{d}(t)+L_{d} \frac{d i_{d}(t)}{d t}-\omega_{e} L_{q} i_{q}(t) \\
& v_{q}(t)=R i_{q}(t)+L_{q} \frac{d i_{q}(t)}{d t}+\omega_{e}\left[\lambda_{d P M}+L_{d} i_{d}(t)\right] \\
& \lambda_{d}(t)=L_{d} i_{d}(t)+\lambda_{d P M} \\
& \lambda_{q}(t)=L_{q} i_{q}(t) \\
& T_{e m}=\frac{3}{2} p\left[\lambda_{P M} i_{q}+\left(L_{d}-L_{q}\right) i_{d} i_{q}\right]
\end{aligned}
$$

where $v_{d}, v_{q}$ are the $d q$-axes voltages, $i_{d}, i_{q}$ are the $d q$ axes currents, $R$ is the stator winding resistance, $L_{d}, L_{q}$ are the $d q$-axes inductances, $p$ is the number of pole pairs, $\omega_{e}$ is the electrical angular speed, $\lambda_{d P M}$ is the permanent magnet flux linkage, $\lambda_{d}, \lambda_{q}$ are the $d q$-axes flux linkages and $T_{e m}$ is the electromagnetic torque. In literature, several modelling approaches, that take into account the saturation effects, have been proposed [15]-[18]. These IPMSM modelling approaches only captures the effects of the fundamental harmonic components.

\section{IPMSM ENHANCED MATHEMATICAL MODEL}

The $d q$-axes flux linkages $\lambda_{d}$ and $\lambda_{q}$ are functions of the $d q$-axes currents $i_{d}, i_{q}$, since the currents are the main source of flux linkages in the IPMSM, and the crosssaturation between the $d$-axis and $q$-axis is inevitably present due to the imperfect construction symmetry of the machine. The spatial harmonics are present also due to the slotting effects and this phenomena is a function of the rotor mechanical position $\theta_{m}$. In order to take into account the effect of saturation, cross-coupling and spatial harmonics effects it is necessary to define $\lambda_{d}$ and $\lambda_{q}$ as functions of the $d q$-axes currents $i_{d}, i_{q}$ and the mechanical rotor position $\theta_{m}$ (or the electrical rotor position $\theta_{e}$ ), as shown in [12], [15] and [19]. The voltage equations of a three-phase IPMSM in $d q$ reference frame are:

$$
\begin{aligned}
& v_{d}(t)=R i_{d}(t)+\frac{d \lambda_{d}(t)}{d t}-\omega_{e} \lambda_{q}(t) \\
& v_{q}(t)=R i_{q}(t)+\frac{d \lambda_{q}(t)}{d t}+\omega_{e} \lambda_{d}(t)
\end{aligned}
$$

The $d q$-axes flux linkages $\lambda_{d}$ and $\lambda_{q}$ are functions of time and, in an equivalent manner when the rotor speed is different than zero, they can be expressed as: $\lambda_{d}(t)=\lambda_{d}\left(i_{d}, i_{q}, \theta_{m}\right)=\lambda_{d i}\left(i_{d}, i_{q}, \theta_{m}\right)+\lambda_{d P M}$

$$
\lambda_{q}(t)=\lambda_{q}\left(i_{d}, i_{q}, \theta_{m}\right)=\lambda_{q i}\left(i_{d}, i_{q}, \theta_{m}\right)+\lambda_{q P M}
$$

where $\lambda_{d i}$ and $\lambda_{q i}$ are the $d q$-axes flux linkages produced by the stator currents excitation and $\lambda_{d P M}$ and $\lambda_{q P M}$ are $d q$-axes flux linkages produced by the permanent magnet (PMs), respectively. Employing the total differential theorem to expand the derivative terms in relationships (6) and (7), the following equations can be derived:

$$
\begin{aligned}
& \frac{d \lambda_{d}(t)}{d t}=\frac{\partial \lambda_{d}\left(i_{d}, i_{q}, \theta_{m}\right)}{\partial i_{d}} \frac{d i_{d}}{d t}+\frac{\partial \lambda_{d}\left(i_{d}, i_{q}, \theta_{m}\right)}{\partial i_{q}} \frac{d i_{q}}{d t}+ \\
& +\frac{\partial \lambda_{d}\left(i_{d}, i_{q}, \theta_{m}\right)}{\partial \theta_{m}} \frac{d \theta_{m}}{d t}= \\
& =L_{d d}^{i n c}\left(i_{d}, i_{q}, \theta_{m}\right) \frac{d i_{d}}{d t}+L_{d q}^{i n c}\left(i_{d}, i_{q}, \theta_{m}\right) \frac{d i_{q}}{d t}+\frac{\partial \lambda_{d}\left(i_{d}, i_{q}, \theta_{m}\right)}{\partial \theta_{m}} \omega_{m}
\end{aligned}
$$

$$
\begin{aligned}
& \frac{d \lambda_{q}(t)}{d t}=\frac{\partial \lambda_{q}\left(i_{d}, i_{q}, \theta_{m}\right)}{\partial i_{d}} \frac{d i_{d}}{d t}+\frac{\partial \lambda_{q}\left(i_{d}, i_{q}, \theta_{m}\right)}{\partial i_{q}} \frac{d i_{q}}{d t}+ \\
& +\frac{\partial \lambda_{q}\left(i_{d}, i_{q}, \theta_{m}\right)}{\partial \theta_{m}} \frac{d \theta_{m}}{d t}= \\
& =L_{q d}^{i n c}\left(i_{d}, i_{q}, \theta_{m}\right) \frac{d i_{d}}{d t}+L_{q q}^{i n c}\left(i_{d}, i_{q}, \theta_{m}\right) \frac{d i_{q}}{d t}+\frac{\partial \lambda_{q}\left(i_{d}, i_{q}, \theta_{m}\right)}{\partial \theta_{m}} \omega_{m}
\end{aligned}
$$

where $L_{d d}^{i n c}$ and $L_{q q}^{i n c}$ are the self-incremental inductances, $L_{d q}{ }_{d q}^{i n c}$ and $L_{q d}{ }^{i n c}$ are the mutual-incremental inductances between the $d$-axis and $q$-axis and $\omega_{m}$ is the mechanical rotor angular speed $\left(\omega_{e}=p \omega_{m}\right)$. The incremental inductances can be defined as the slope of the tangent at the magnetization curve operating point. In particular, the incremental inductance can be calculated by $L_{\text {inc }}=\square \lambda / \square i$, whereas the apparent inductances can be calculated by $L_{a p p}=\lambda / I$ [13]. In order to obtain the values of the apparent and incremental inductances, the IPMSM $d q$-axes flux linkages must be evaluated for several working conditions by fixing the current values. This requires a large number of experimental investigations on the IPMSM under test or a large number of finite-element analysis (FEA) simulations. Since the $d q$-axes flux linkages are nonlinear functions of $d q$-axes currents, consequently the apparent and incremental inductances are also nonlinear functions of $d q$-axes currents. In steady state condition, the $d q$-axes flux linkages equations (8) and (9) can be expanded in the following way:

$$
\begin{aligned}
& \lambda_{d}\left(i_{d}, i_{q}, \theta_{m}\right)=\lambda_{d i}\left(i_{d}, i_{q}, \theta_{m}\right)+\lambda_{d P M}= \\
& =\lambda_{d d}\left(i_{d}, i_{q}, \theta_{m}\right)+\lambda_{d q}\left(i_{d}, i_{q}, \theta_{m}\right)+\lambda_{d P M}
\end{aligned}
$$




$$
\begin{aligned}
& \lambda_{q}\left(i_{d}, i_{q}, \theta_{m}\right)=\lambda_{q i}\left(i_{d}, i_{q}, \theta_{m}\right)+\lambda_{q P M}= \\
& =\lambda_{q d}\left(i_{d}, i_{q}, \theta_{m}\right)+\lambda_{q q}\left(i_{d}, i_{q}, \theta_{m}\right)+\lambda_{q P M}
\end{aligned}
$$

where $\lambda_{d d}$ is the $d$-axis flux linkage produced by $d$-axis current, $\lambda_{d q}$ is the $d$-axis flux linkage produced by $q$-axis current, the $\lambda_{q q}$ is the $q$-axis flux linkage produced by $q$ axis current and the $\lambda_{q d}$ is the $q$-axis flux linkage produced by $d$-axis current. The $d q$-axes flux linkages $\lambda_{d}$ and $\lambda_{q}$ can be expressed by the use of apparent inductances with the following relationships:

$$
\begin{aligned}
& \lambda_{d}\left(i_{d}, i_{q}, \theta_{m}\right)=\lambda_{d i}\left(i_{d}, i_{q}, \theta_{m}\right)+\lambda_{d P M}= \\
& L_{d d}^{a p p}\left(i_{d}, i_{q}, \theta_{m}\right) i_{d}+L_{d q}^{a p p}\left(i_{d}, i_{q}, \theta_{m}\right) i_{q}+\lambda_{d P M} \\
& \lambda_{q}\left(i_{d}, i_{q}, \theta_{m}\right)=\lambda_{q i}\left(i_{d}, i_{q}, \theta_{m}\right)+\lambda_{q P M}= \\
& L_{q d}^{a p p}\left(i_{d}, i_{q}, \theta_{m}\right) i_{d}+L_{q q}^{a p p}\left(i_{d}, i_{q}, \theta_{m}\right) i_{q}+\lambda_{q P M}
\end{aligned}
$$

where $L_{d d}^{a p p}$ and $L_{q q}^{a p p}$ are the self-apparent inductances, $L_{d q}{ }^{a p p}$ and $L_{q d}{ }^{a p p}$ are the mutual-apparent inductances between the $d$-axis and $q$-axis. It is possible to define the apparent inductances matrix as:

$$
L_{d q}^{a p p}\left(i_{d}, i_{q}, \theta_{m}\right)=\left[\begin{array}{ll}
L_{d d}^{a p p}(t)\left(i_{d}, i_{q}, \theta_{m}\right) & L_{d q}^{a p p}(t)\left(i_{d}, i_{q}, \theta_{m}\right) \\
L_{q d}^{a p p}(t)\left(i_{d}, i_{q}, \theta_{m}\right) & L_{q q}^{a p p}(t)\left(i_{d}, i_{q}, \theta_{m}\right)
\end{array}\right]
$$

This matrix can be simplified with a mathematical adjustment and the following non-coupled apparent inductances are defined as:

$$
\begin{aligned}
& L_{d}^{a p p}\left(i_{d}, i_{q}, \theta_{m}\right)=\frac{L_{d d}^{a p p}\left(i_{d}, i_{q}, \theta_{m}\right) i_{d}+L_{d q}^{a p p}\left(i_{d}, i_{q}, \theta_{m}\right) i_{q}}{i_{d}} \\
& L_{q}^{a p p}\left(i_{d}, i_{q}, \theta_{m}\right)=\frac{L_{q d}^{a p p}\left(i_{d}, i_{q}, \theta_{m}\right) i_{d}+L_{q q}^{a p p}\left(i_{d}, i_{q}, \theta_{m}\right) i_{q}}{i_{q}} \\
& L_{d q-a d j}^{a p p}\left(i_{d}, i_{q}, \theta_{m}\right)=\left[\begin{array}{cc}
L_{d}^{a p p}\left(i_{d}, i_{q}, \theta_{m}\right) & 0 \\
0 & L_{q}^{a p p}\left(i_{d}, i_{q}, \theta_{m}\right)
\end{array}\right]
\end{aligned}
$$

where $L_{d}^{a p p}$ and $L_{q}^{a p p}$ are the $d q$-axes non-coupled apparent inductances. The calculation of the $d q$-axes noncoupled apparent inductances are easier than of the apparent inductances quantity present in (19) because they require only the values of the $d q$-axes flux linkages produced by the stator currents excitation $\lambda_{d i}$ and $\lambda_{q i}$ and not of each component of $d q$-axes flux linkages. In detail, the $d q$-axes non-coupled apparent inductances can be determined with the following relationships:

$$
L_{d}^{a p p}\left(i_{d}, i_{q}, \theta_{m}\right)=\frac{\lambda_{d i}\left(i_{d}, i_{q}, \theta_{m}\right)}{i_{d}}
$$

$L_{q}^{a p p}\left(i_{d}, i_{q}, \theta_{m}\right)=\frac{\lambda_{q i}\left(i_{d}, i_{q}, \theta_{m}\right)}{i_{q}}$

The $d q$-axes flux linkages can be defined with the following relationships:

$\lambda_{d}\left(i_{d}, i_{q}, \theta_{m}\right)=L_{d}^{a p p}\left(i_{d}, i_{q}, \theta_{m}\right) i_{d}+\lambda_{d P M}$

$\lambda_{q}\left(i_{d}, i_{q}, \theta_{m}\right)=L_{q}^{a p p}\left(i_{d}, i_{q}, \theta_{m}\right) i_{q}+\lambda_{q P M}$

Therefore, the IPMSM voltage equations that take into account the saturation, cross-coupling and spatial harmonics effects are:

$$
\begin{aligned}
& v_{d}(t)=R i_{d}(t)+L_{d d}^{i n c}\left(i_{d}, i_{q}, \theta_{m}\right) \frac{d i_{d}}{d t}+L_{d q}^{i n c}\left(i_{d}, i_{q}, \theta_{m}\right) \frac{d i_{q}}{d t}+ \\
& +\frac{\partial \lambda_{d}\left(i_{d}, i_{q}, \theta_{m}\right)}{\partial \theta_{m}} \omega_{m}-\omega_{e}\left[L_{q}^{a p p}\left(i_{d}, i_{q}, \theta_{m}\right) i_{q}+\lambda_{q P M}\right]
\end{aligned}
$$

$v_{q}(t)=R i_{q}(t)+L_{q d}^{i n c}\left(i_{d}, i_{q}, \theta_{m}\right) \frac{d i_{d}}{d t}+L_{q q}^{i n c}\left(i_{d}, i_{q}, \theta_{m}\right) \frac{d i_{q}}{d t}$

$+\frac{\partial \lambda_{q}\left(i_{d}, i_{q}, \theta_{m}\right)}{\partial \theta_{m}} \omega_{m}+\omega_{e}\left[L_{d}^{a p p}\left(i_{d}, i_{q}, \theta_{m}\right) i_{d}+\lambda_{d P M}\right]$

In detail, it is possible to see that incremental inductances define the dynamic behaviour of IPMSM. While the apparent inductances define the amount of the $d q$-axes flux linkages at specific $d q$-axes currents values and, consequently, the $d q$-axes motional induced voltages due to flux linkage moving at steady-state conditions. Generically the flux linkage $\lambda_{q P M}$ presents a very low value and can be neglected.

The torque equation of IPMSM considering the saturation, cross-coupling, and spatial harmonics effects can be derived from the power relationships in $d q$ reference frame. In this study the iron and mechanical losses are considered absent, while the temperature and the energy stored in the PMs are considered constant. The input power in $d q$-reference frame is:

$$
\begin{aligned}
& P_{d q}=v_{d} i_{d}+v_{q} i_{q}=R\left(i_{d}^{2}+i_{q}^{2}\right)+ \\
& +\left[L_{d d}^{i n c}\left(i_{d}, i_{q}, \theta_{m}\right) \frac{d i_{d}}{d t} i_{d}+L_{d q}^{i n c}\left(i_{d}, i_{q}, \theta_{m}\right) \frac{d i_{q}}{d t} i_{d}+\right. \\
& \left.L_{q d}^{i n c}\left(i_{d}, i_{q}, \theta_{m}\right) \frac{d i_{d}}{d t} i_{q}+L_{q q}^{i n c}\left(i_{d}, i_{q}, \theta_{m}\right) \frac{d i_{q}}{d t}{ }_{q}\right]+ \\
& +\left[\omega_{e}\left(\lambda_{d} i_{q}-\lambda_{q} i_{d}\right)+\omega_{m} \frac{\partial \lambda_{d}\left(i_{d}, i_{q}, \theta_{m}\right)}{\partial \theta_{m}} i_{d}+\right. \\
& \left.+\omega_{m} \frac{\partial \lambda_{q}\left(i_{d}, i_{q}, \theta_{m}\right)}{\partial \theta_{m}} i_{q}\right]=P_{d q 1}+P_{d q 2}+P_{d q 3}
\end{aligned}
$$


where $P_{d q 1}$ is the copper power loss, $P_{d q 2}$ is the power associated with the stored energy in the magnetic field, and $P_{d q 3}$ is the mechanical power. Since it is assumed that no zero sequence currents exists in the system (star connected machine), the zero sequence power is equal to zero. Therefore, the mechanical power of the IPMSM is:

$$
\begin{aligned}
& P_{m}=\frac{3}{2}\left[\omega_{e}\left(\lambda_{d} i_{q}-\lambda_{q} i_{d}\right)+\omega_{m} \frac{\partial \lambda_{d}\left(i_{d}, i_{q}, \theta_{m}\right)}{\partial \theta_{m}} i_{d}+\right. \\
& \left.+\omega_{m} \frac{\partial \lambda_{q}\left(i_{d}, i_{q}, \theta_{m}\right)}{\partial \theta_{m}} i_{q}\right]
\end{aligned}
$$

The electromagnetic torque can be calculated with the following relationship:

$$
\begin{aligned}
& T_{e m}=\frac{P_{m}}{\omega_{m}}=\frac{3}{2} p\left(\lambda_{d} i_{q}-\lambda_{q} i_{d}\right)+\frac{3}{2}\left[\frac{\partial \lambda_{d}\left(i_{d}, i_{q}, \theta_{m}\right)}{\partial \theta_{m}} i_{d}+\right. \\
& \left.+\frac{\partial \lambda_{q}\left(i_{d}, i_{q}, \theta_{m}\right)}{\partial \theta_{m}} i_{q}\right]
\end{aligned}
$$

Replacing the flux linkage equations (22) and (23) in the torque equation (28), the derived torque equation is:

$$
\begin{aligned}
& T_{e m}=\frac{P_{m}}{\omega_{m}}=\frac{3}{2} p\left\{\left(\lambda_{d P M} i_{q}-\lambda_{q P M} i_{d}\right)+\right. \\
& \left.+\left[L_{d}^{a p p}\left(i_{d}, i_{q}, \theta_{m}\right)-L_{q}^{a p p}\left(i_{d}, i_{q}, \theta_{m}\right)\right]_{d} i_{q}\right\}+ \\
& +\frac{3}{2}\left[\frac{\partial \lambda_{d}\left(i_{d}, i_{q}, \theta_{m}\right)}{\partial \theta_{m}} i_{d}+\frac{\partial \lambda_{q}\left(i_{d}, i_{q}, \theta_{m}\right)}{\partial \theta_{m}} i_{q}\right]=T_{e m 1}+T_{e m 2}
\end{aligned}
$$

$T_{e m 1}=\frac{3}{2} p\left\{\left(\lambda_{d P M} i_{q}-\lambda_{q P M} i_{d}\right)+\right.$

$\left.+\left[L_{d}^{a p p}\left(i_{d}, i_{q}, \theta_{m}\right)-L_{q}^{a p p}\left(i_{d}, i_{q}, \theta_{m}\right)\right] i_{d} i_{q}\right\}$

$T_{e m 2}=+\frac{3}{2}\left[\frac{\partial \lambda_{d}\left(i_{d}, i_{q}, \theta_{m}\right)}{\partial \theta_{m}} i_{d}+\frac{\partial \lambda_{q}\left(i_{d}, i_{q}, \theta_{m}\right)}{\partial \theta_{m}} i_{q}\right]$

where the torque component $T_{e m l}$ is similar respect the torque equation of the conventional modelling approach and, since the apparent inductance are functions of $i_{d}, i_{q}$ and $\theta_{m}, T_{e m 1}$ represents the mainly average torque of IPMSM plus some ripple torque component. Instead, the torque component $T_{e m 2}$ is an additional ripple torque component of IPMSM due by the variation of $d q$-axes flux linkages with the rotor position $\theta_{m}$.

\section{IPMSM UNDER STUDY AND ITS CHARACTERIZATION}

In order to validate the effectiveness of the proposed enhanced IPMSM mathematical model, a three phase IPMSM with tangentially magnetization is considered and simulated in FEA software. The cross-sectional view of the IPMSM is shown in Fig. 1. The IPMSM main electrical, mechanical and geometrical data are summarized in Table 1. The iron pack magnetic material is a $0.5 \mathrm{~mm}$ wide laminated sheet of type M330-50A while the PMs are made by SMCo-18 MGOe. The SMCo18 MGOe magnets B-H curves are shown in Fig. 2.

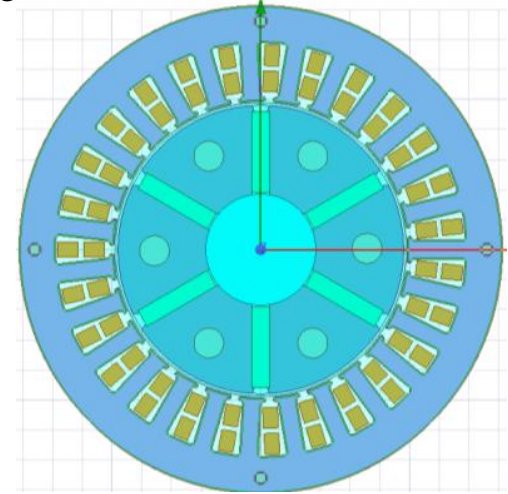

Fig. 1 Cross-section of IPMSM under test.

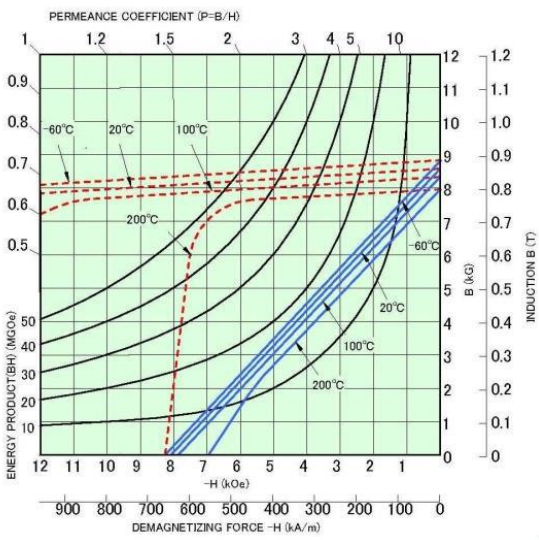

Fig. 2 B-H curves of SMCo-18 MGOe PMs.

TABLE 1 ELECTRICAL AND MECHANICAL DATA OF THE IPMSM UNDER TEST.

\begin{tabular}{c|c} 
Quantity & Value \\
\hline Power [kW] & 0.8 \\
\hline Rated current [A] & 3.6 \\
\hline Nominal Speed [rpm] & 4000 \\
\hline Maximum Speed [rpm] & 6000 \\
\hline Nr. of pole pairs & 3 \\
\hline Nr. of phases & 3 \\
\hline Nominal torque [Nm] & 1.8 \\
\hline Peak torque [Nm] & 9.2 \\
\hline Nr. of stator slot & 27 \\
\hline Axial stator length [mm] & 59 \\
\hline External stator diameter [mm] & 81 \\
\hline Inner stator diameter [mm] & 49.6 \\
\hline External rotor diameter [mm] & 48 \\
\hline Inner rotor diameter [mm] & 19
\end{tabular}

The goal of the FEA investigations concerns the determination of flux and torque mapping of IPMSM under test. The $d q$-axes flux linkages $\lambda_{d}, \lambda_{q}$ and electromagnetic torque $T_{e m}$ mapping are obtained by varying the quantities $i_{d}, i_{q}$ and $\theta_{e}$ in the range [-7.5 A-7.5 
A], $\left[\begin{array}{lll}0 & \mathrm{~A}-7.5 \mathrm{~A}\end{array}\right]$ and $\left[0^{\circ}-360^{\circ}\right]$, respectively. Negative values of the $q$-axis current $i_{q}$ are not taken into account because this IPMSM is used only for motor operation. The $i_{d}, i_{q}$ and $\theta_{e}$ samples in the FE calculations are 30, 16 and 49 , respectively, and the total number of FEA simulations carried out are 23250. The $d q$-axes flux linkages values, in each FEA simulations, are obtained from the flux linkage in $a b c$-reference frame with the $d q o$ Park transformation. By way of example, the $d q$-axes flux linkages and the electromagnetic torque maps as function of $d q$-axes currents at $0^{\circ}$ rotor electrical position are shown in Fig. 3-Fig. 5, respectively.

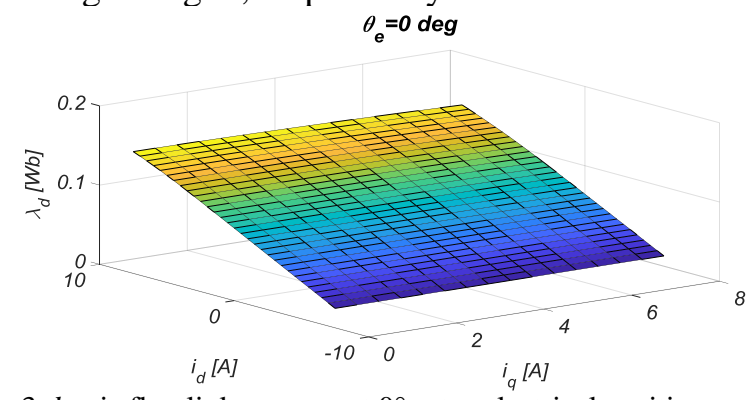

Fig. $3 d$-axis flux linkage map at $0^{\circ}$ rotor electrical position.

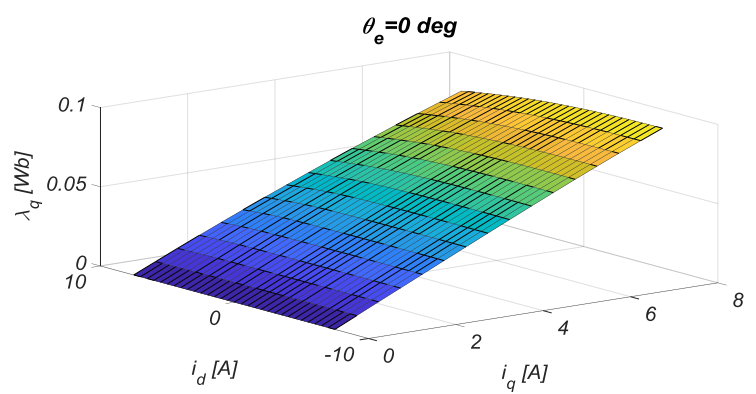

Fig. $4 q$-axis flux linkage map at $0^{\circ}$ rotor electrical position.

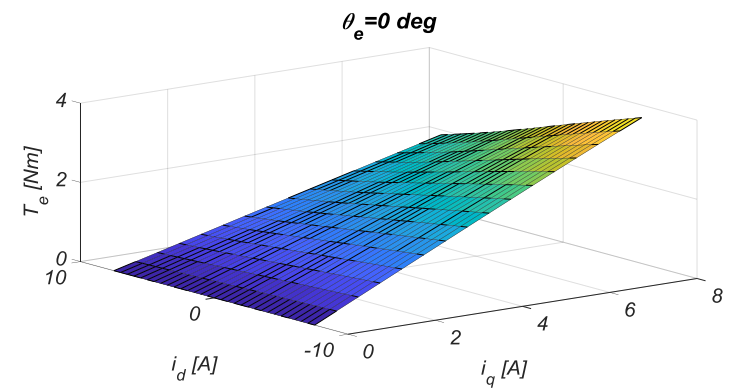

Fig. 5 Torque map at $0^{\circ}$ rotor electrical position.

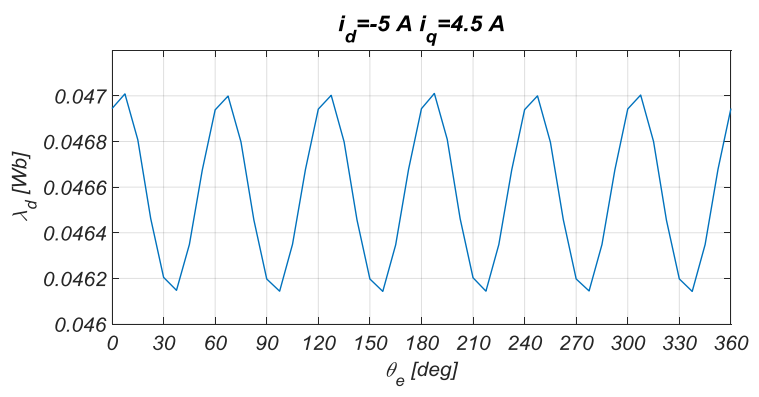

Fig. $6 d$-axis flux linkage variation with rotor electrical position at $i_{d}=-5 \mathrm{~A}$ and $i_{q}=4.5 \mathrm{~A}$.

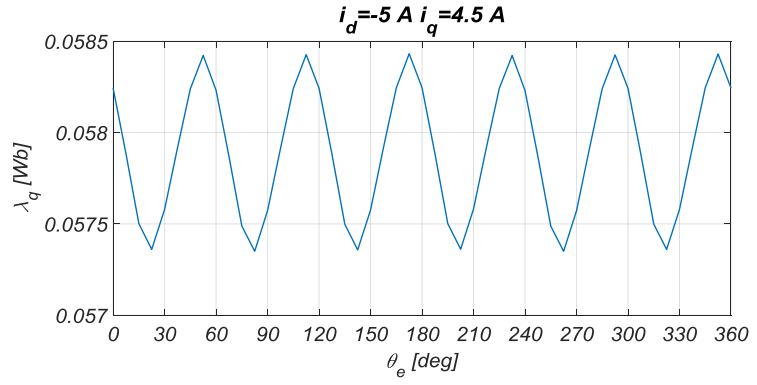

Fig. $7 q$-axis flux linkage variation with rotor electrical position at $i_{d}=-5 \mathrm{~A}$ and $i_{q}=4.5 \mathrm{~A}$.

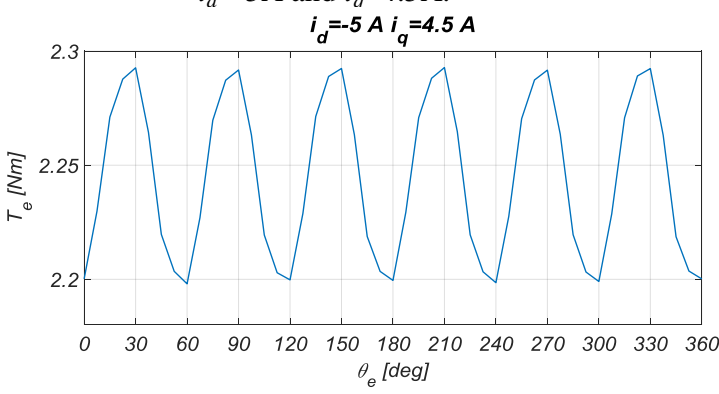

Fig. 8 Electromagnetic torque variation with rotor electrical position at $i_{d}=-5 \mathrm{~A}$ and $i_{q}=4.5 \mathrm{~A}$.

Moreover, the variation of $d q$-axes flux linkages and torque as a function of the rotor electrical position for fixed values of $d q$-axes currents $\left(i_{d}=-5 \mathrm{~A}, i_{q}=4.5 \mathrm{~A}\right)$ are reported in Fig. 6-Fig. 8, respectively. The magnetic saturation effect can be observed in the $q$-axis flux linkage map (Fig. 4) and the spatial harmonics are evident in the Fig. 6-Fig. 8.

\section{SIMULINK MODEL AND VALIDATION}

The proposed enhanced mathematical model has been implemented in Matlab ${ }^{\circledR} /$ Simulink environment and validated by means of several FEA simulations carried out. The implementation of the proposed mathematical model in Simulink environment can be very useful since it allows to evaluate the electromagnetic behaviour of the IPMSM in various operating conditions with much smaller computational times than those required for simulations in the FEA environment. Moreover, a high fidelity model of the IPMSM implemented in Simulink environment is of considerable utility for control purpose. In the first analysis, the fidelity of the IPMSM conventional modelling approach with the FEA results has been investigated and described below. Subsequently the validation of the proposed enhanced IPMSM mathematical model is presented and discussed.

\section{A. IPMSM conventional mathematical model}

The IPMSM conventional mathematical model (CMM) employs constant value of the electrical and magnetic parameters. These values are calculated as the mean value in the investigated current range and they are reported in Table 2. 
TABLE 2 CMM PARAMETERS VALUES

\begin{tabular}{c|c} 
Parameter & Value \\
\hline PM flux linkage $\lambda_{d P M}[\mathrm{~Wb}]$ & 0.0913 \\
\hline$d$-axis inductance $L_{d}[\mathrm{H}]$ & 0.0088 \\
\hline$q$-axis inductance $L_{q}[\mathrm{H}]$ & 0.0125 \\
\hline Stator resistance $R[\Omega]$ & 2.21
\end{tabular}

Starting from this quantities values, the $d q$-axes flux linkages and the electromagnetic torque are calculated with the equations (3-5) and compared with the $d q$-axes flux linkages and the electromagnetic torque obtained in FEA simulations at the same $d q$-axes currents values. In order to investigate the fidelity of the CMM of the IPMSM at steady state condition, the following percentage error quantities are defined:

$$
\begin{aligned}
& \operatorname{err}_{\lambda_{d} C M M} \%=\frac{\lambda_{d-F E A}-\lambda_{d-C M M}}{\lambda_{d-F E A}} 100 \\
& \operatorname{err}_{\lambda_{q} C M M} \%=\frac{\lambda_{q-F E A}-\lambda_{q-C M M}}{\lambda_{q-F E A}} 100 \\
& \operatorname{err}_{T_{e m} C M M} \%=\frac{T_{e m-F E A}-T_{e m-C M M}}{T_{e m-F E A}} 100
\end{aligned}
$$

where $\lambda_{d-F E A}, \lambda_{q-F E A}$ and $T_{e m-F E A}$ are the $d q$-axes flux linkage and the electromagnetic torque mean values evaluated in FEA investigations, while $\lambda_{d-C M M}, \lambda_{q-\text {-CMM }}$ and $T_{\text {em-CMM }}$ are the $d q$-axes flux linkage and the electromagnetic torque mean values evaluated with the IPMSM conventional mathematical model. The $d$-axis flux linkage error map, $q$-axis flux linkage error map and the torque error map are reported in Fig. 9-Fig. 11, respectively. It is possible to observe that $d$-axis flux error values decreases as the $d$-axis current decreases or in the weakening flux operating points, the $q$-axis flux error values decreases as the $q$-axis current increases. Whereas the torque error map present a nonlinear trend. In addition, the absolute maximum percentage error value detected for each quantity of interest are reported in Table 3.

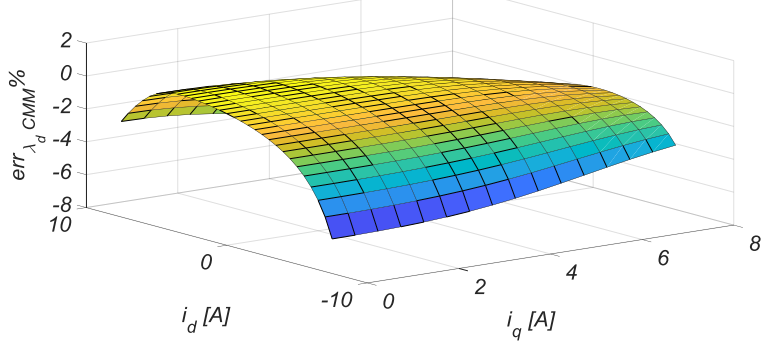

Fig. $9 d$-axis flux error map of the IPMSM conventional mathematical model.

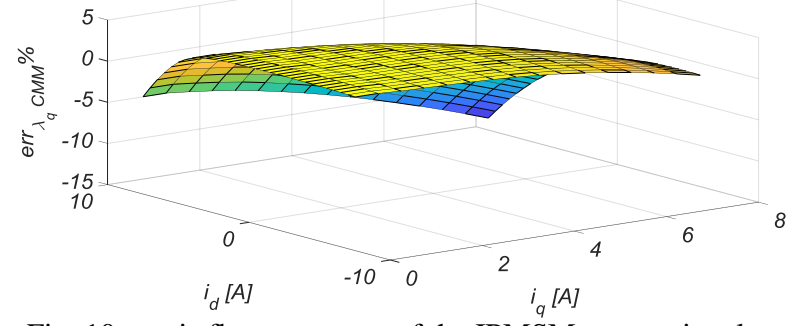

Fig. $10 q$-axis flux error map of the IPMSM conventional mathematical model.

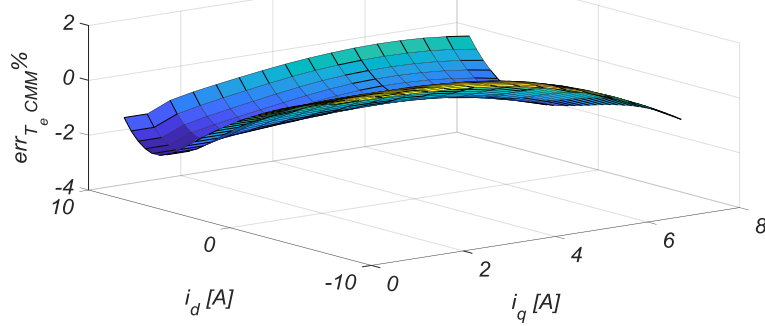

Fig. 11 Torque error map of the IPMSM conventional mathematica model.

TABLE 3 ABSOLUTE MAXIMUM PERCENTAGE ERROR VALUES

\begin{tabular}{c|c} 
Quantity & Value \\
\hline Absolute maximum err $_{\lambda d}$ CMM $\%$ & $7.01 \%$ \\
\hline Absolute maximum err $_{\lambda q}$ CMM $\%$ & $12.35 \%$ \\
\hline Absolute maximum err $_{T \text { em }}$ CMM $\%$ & $2.5 \%$
\end{tabular}

Therefore, from the analysis carried out, it is possible to observe that the IPMSM conventional mathematical modelling approach predicts in accurate way the quantities of interest at low values of the $d q$-axes current where the magnetic behaviour of the machine is almost linear and its use is not suitable in the IPMSM flux weakening operating region where the machine can be operates at high saturation level.

\section{B. IPMSM enhanced mathematical model}

The proposed IPMSM enhanced mathematical model has been implemented in Matlab ${ }^{\circledR} /$ Simulink environment and its schematic representation is reported in Fig. 12. In detail, the schematic representation considers also the mechanical equation reported below:

$T_{e m}=T_{L}+F \omega_{m}+j \frac{d \omega_{m}}{d t}$

where $T_{L}$ is the load torque, $F$ is the viscous friction coefficient and $j$ is the inertia moment. The values of the $d q$-axes non-coupled apparent inductances, the $d q$-axes incremental inductances, the $d q$-axes flux linkage produced by the PMs and of the $d q$-axes flux linkages derivative terms, obtained by the characterization carried out in FEA environment, are implemented as lookup tables (LUT). 


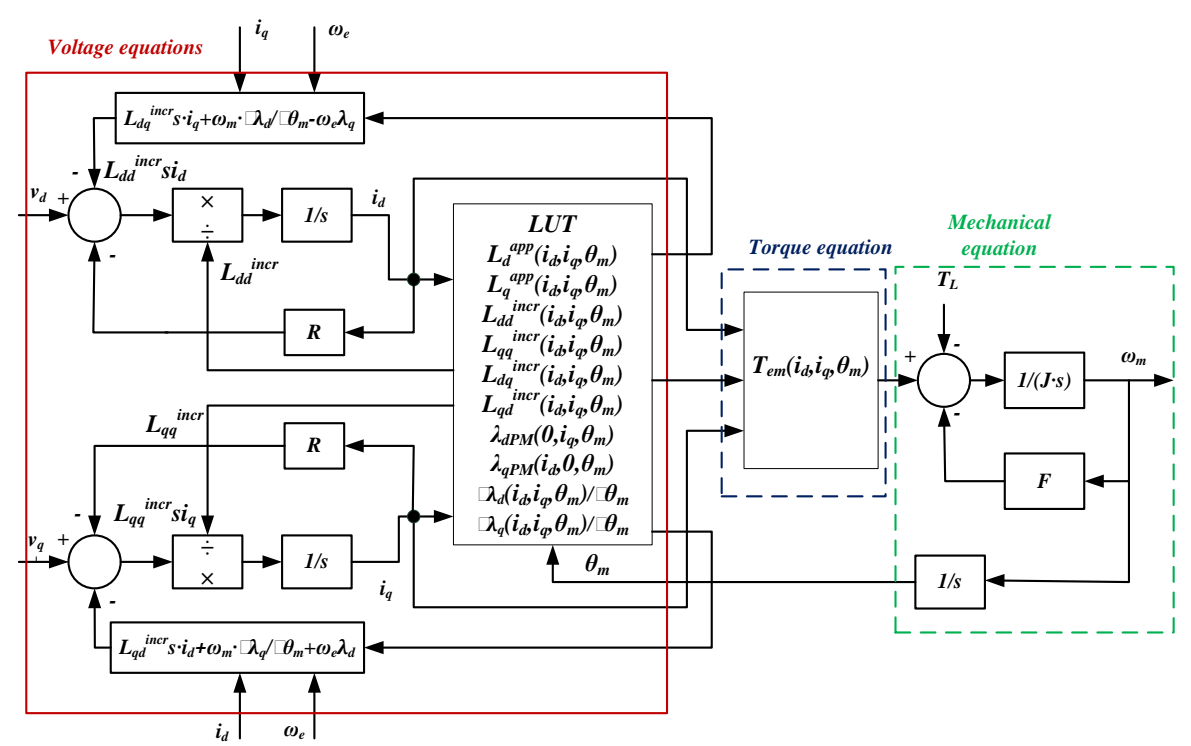

Fig. 12 Schematic representation of the IPMSM enhanced mathematical model.

High number of representative operating points with different speed and load conditions are investigated for validation purpose. In detail, a field oriented control drive system with the proposed IPMSM enhanced model is simulated for each working points of interest and the current waveforms are extracted and used as input quantities in the current FE model at the same speed condition. Two operating points at nominal speed are showed and discussed. In the first case under study, the IPMSM operates at $4000 \mathrm{rpm}, 0.4103 \mathrm{Nm}$ which correspond $d$ - and $q$-axis current mean values equal to $0 \mathrm{~A}$ and $1 \mathrm{~A}$, respectively. The comparison between the waveforms of the quantities of interest detected with the proposed Simulink model and the FE model, such as the input $d q$-axes currents, the electromagnetic torque and the input $d q$-axes voltages are reported in Fig. 13-Fig. 16, respectively. The electromagnetic torque waveforms predicted by the proposed enhanced mathematical Simulink model and FE model are almost coincident. Similar results are obtained for the $d q$-axes voltages waveforms where a slightly difference is detected on the $d$-axis voltages mean values. This results can be associated to the fact that in FEA environment, the $d q$ axes induced voltages are calculated from the derivatives of flux linkages and the accuracy depends on the size of the transient steps.

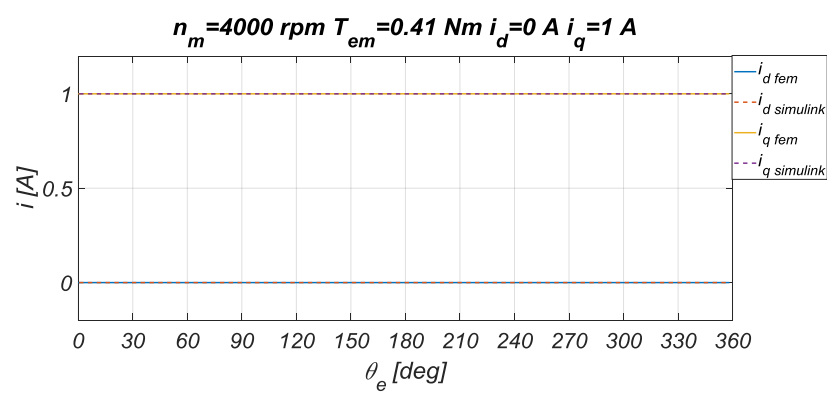

Fig. $13 d q$-axes currents comparison at $4000 \mathrm{rpm}, 0.41 \mathrm{Nm}$.

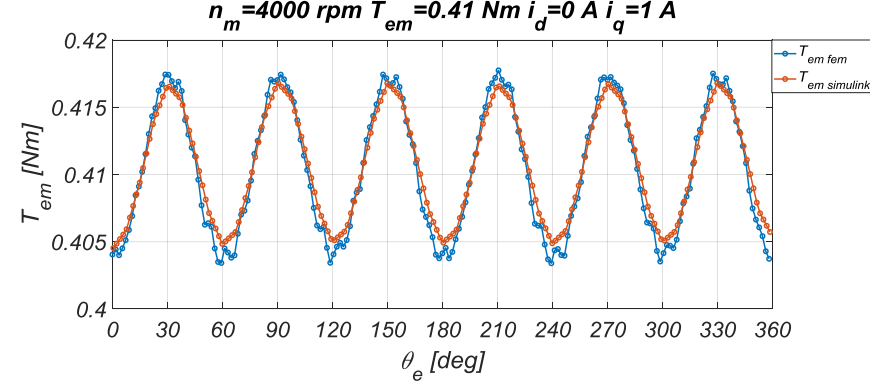

Fig. 14 Electromagnetic torques comparison at $4000 \mathrm{rpm}, 0.41 \mathrm{Nm}$.

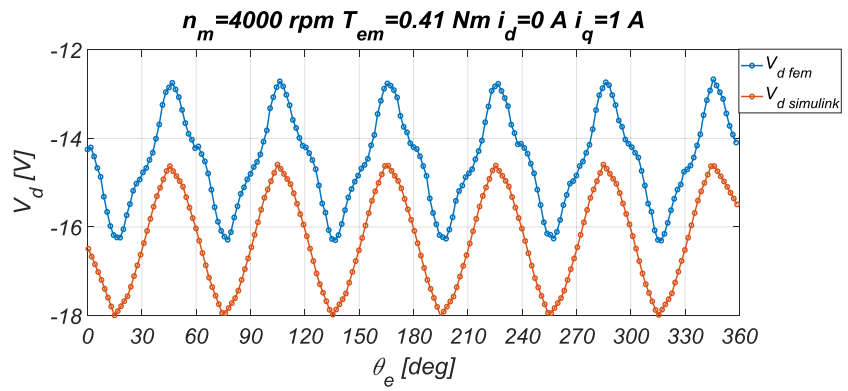

Fig. $15 d$-axis voltages comparison at $4000 \mathrm{rpm}, 0.41 \mathrm{Nm}$.

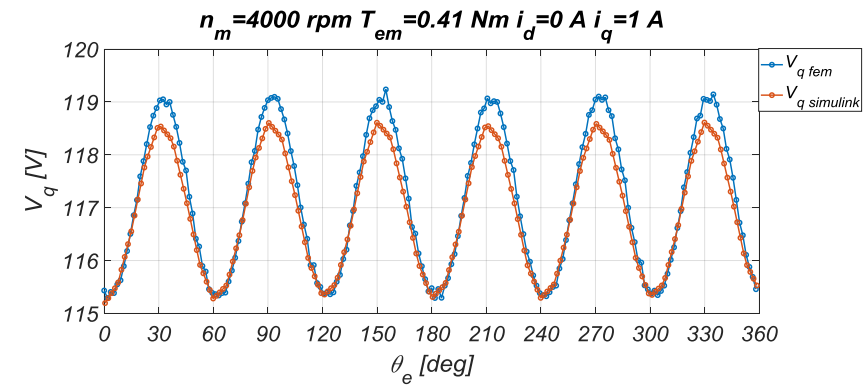

Fig. $16 q$-axis voltages comparison at $4000 \mathrm{rpm}, 0.41 \mathrm{Nm}$.

The second case under study considers a IPMSM operating point in the weakening flux operating region where the IPMSM operates at $4000 \mathrm{rpm}, 2.3145 \mathrm{Nm}$ which correspond $d$-and $q$-axis current mean values equal 
to $-3 \mathrm{~A}$ and $5 \mathrm{~A}$, respectively. The comparison between the input $d q$-axes currents waveforms, the electromagnetic torque waveforms and the input $d q$-axes voltages waveforms predicted with the with the proposed Simulink model and the FE model are reported in Fig. 17-Fig. 20, respectively.

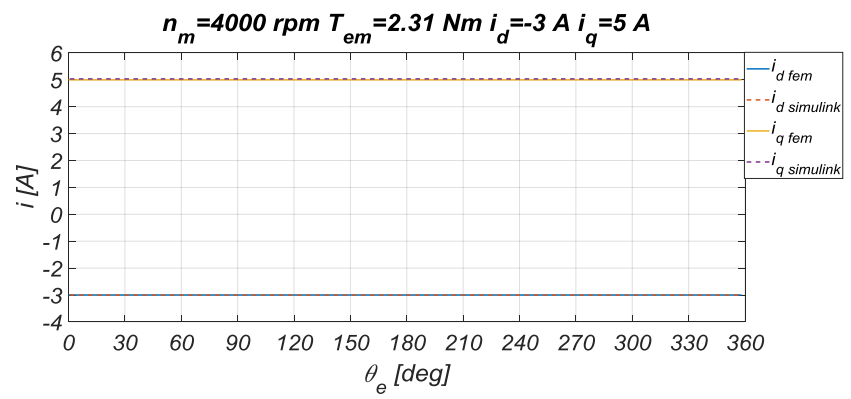

Fig. $17 d q$-axes currents comparison at $4000 \mathrm{rpm}, 2.31 \mathrm{Nm}$.

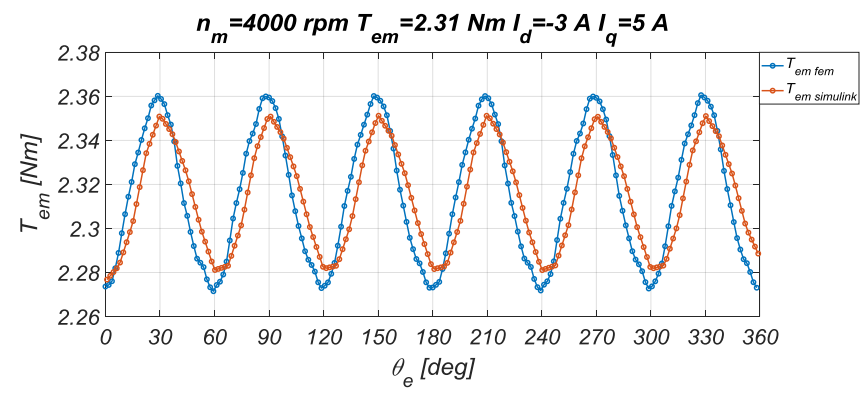

Fig. 18 Electromagnetic torques comparison at $4000 \mathrm{rpm}, 2.31 \mathrm{Nm}$.

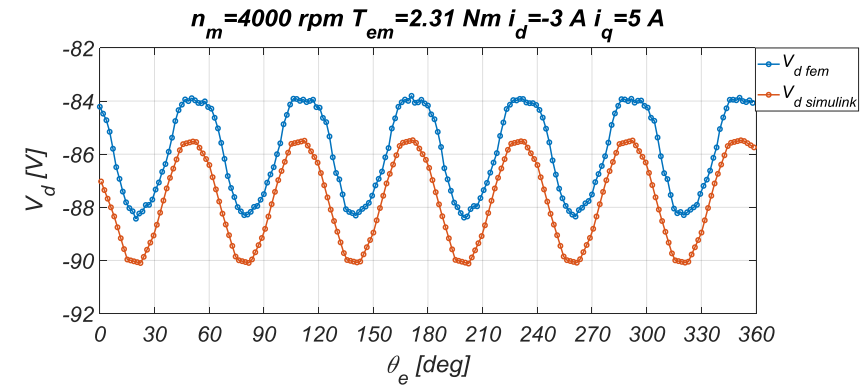

Fig. $19 d$-axis voltages comparison at $4000 \mathrm{rpm}, 2.31 \mathrm{Nm}$.

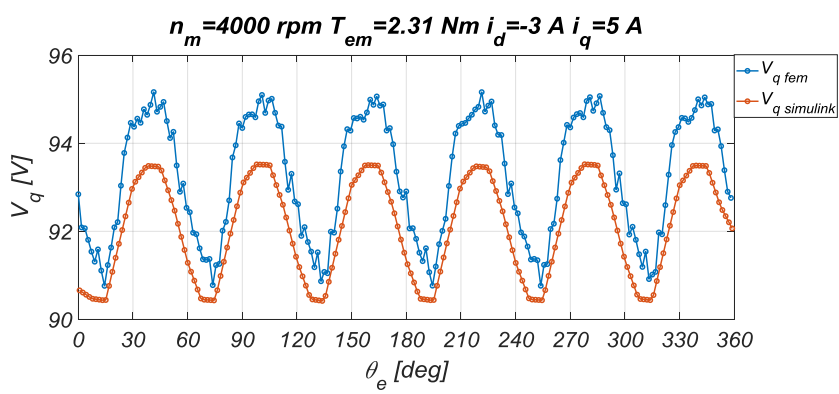

Fig. $20 q$-axis voltages comparison at $4000 \mathrm{rpm}, 2.31 \mathrm{Nm}$.

In this case of study a slightly difference is detected on the electromagnetic torque waveforms but not in the mean values. Similar results are obtained for the $d q$-axes voltages waveforms. These results can be to associated to the size of the transient step of the FEA simulations but they can considered satisfactory for the validation purpose. Similar results have been obtained in the other representative operating points of the IPMSM.

\section{CONCLUSION}

The paper presents an enhanced mathematical modelling approach of the IPMSMs. The proposed model allows to predict all significant effects associated to the saturation, cross-coupling and spatial harmonics phenomena. In detail, the proposed IPMSM enhanced mathematical model has been implemented in Matlab ${ }^{\circledR} /$ Simulink environments and validated by means several FEA simulations. The results obtained demonstrate as the proposed model present a high fidelity and computational efficient behaviour and it can be of considerable help for the design, development of innovative control algorithms and for the evaluation of the drive performances. In the future works we will try to perform an experimental validation of the proposed modelling approach and extend this modelling approach considering the effects due to the presence of the iron losses and the presence of zero sequence components.

\section{ACKNOWLEDGMENT}

This work was financially supported by PON R\&I 2015-2020 "Propulsione e Sistemi Ibridi per velivoli ad ala fissa e rotante - PROSIB", CUP no:B66C18000290005, by H2020-ECSEL-2017-1-IAtwo-stage "first and european sic eightinches pilot lineREACTION", by Prin 2017- Settore/Ambito di intervento: PE7 linea C - Advanced power-trains and systems for full electric aircrafts, by PON R\&I 20142020 - AIM (Attraction and International Mobility), project AIM1851228-1 and by ARS01_00459-PRJ-0052 ADAS+ "Sviluppo di tecnologie e sistemi avanzati per la sicurezza dell'auto mediante piattaforme ADAS".

\section{REFERENCES}

[1] I. Boldea, L. N. Tutelea, L. Parsa, and D. Dorrell, "Automotive electric propulsion systems with reduced or no permanent magnets: An overview,” IEEE Trans. Ind. Electron., vol. 61, no. 10, pp. 5696-5711, Oct. 2014.

[2] Z. Yang, F. Shang, I. P. Brown and M. Krishnamurthy, "Comparative Study of Interior Permanent Magnet, Induction, and Switched Reluctance Motor Drives for EV and HEV Applications," in IEEE Transactions on Transportation Electrification, vol. 1, no. 3, pp. 245-254, Oct. 2015.

[3] H. Lin, H. Guo and H. Qian, "Design of High- Performance Permanent Magnet Synchronous Motor for Electric Aircraft Propulsion," 2018 21st International Conference on Electrical Machines and Systems (ICEMS), Jeju, 2018, pp. 174-179.

[4] Sarlioglu and C. T. Morris, "More electric aircraft: Review, challenges, and opportunities for commercial transport aircraft," IEEE Trans. Transport. Electrific., vol. 1, no. 1, pp. 54-64, Jun. 2015.

[5] G. Sulligoi, A. Vicenzutti and R. Menis, "All-Electric Ship Design: From Electrical Propulsion to Integrated Electrical and Electronic Power Systems," in IEEE Transactions on 
Transportation Electrification, vol. 2, no. 4, pp. 507-521, Dec. 2016.

[6] A. Kasha, R. Lin, S. Sudhoff, J. Chalfant and J. Alsawalhi, "A comparison of permanent magnet machine topologies for marine propulsion applications," 2017 IEEE Electric Ship Technologies Symposium (ESTS), Arlington, VA, 2017, pp. 437-444.

[7] M. Caruso, A. O. Di Tommaso, M. Lombardo, R. Miceli, C. Nevoloso and C. Spataro, "Experimental comparison of two control algorithms for low-saliency ratio interior permanent magnet synchronous motors," 2018 Thirteenth International Conference on Ecological Vehicles and Renewable Energies (EVER), Monte-Carlo, 2018, pp. 1-6.

[8] Caruso, M.; di Tommaso, A.O.; Miceli, R.; Nevoloso, C.; Spataro, C.; Trapanese, M. Maximum Torque per Ampere Control Strategy for Low-Saliency Ratio IPMSMs. Int. J. Renew. Energy Res. 2019, 9, 374-383.

[9] V. Castiglia, P. Ciotta, A. O. Di Tommaso, R. Miceli and C. Nevoloso, "High Performance FOC for Induction Motors with Low Cost ATSAM3X8E Microcontroller," 2018 7th International Conference on Renewable Energy Research and Applications (ICRERA), Paris, 2018, pp. 1495-1500.

[10] A. Bruno, M. Caruso, A. O. D. Tommaso, C. Nevoloso and R. Miceli, "Experimental Comparison of Efficiency Enhancement Algorithms for Three-Phase Induction Motors," 2019 Fourteenth International Conference on Ecological Vehicles and Renewable Energies (EVER), Monte-Carlo, Monaco, 2019.

[11] S. Wendel, P. Karamanakos, A. Dietz and R. Kennel, "Operating Point Dependent Variable Switching Point Predictive Current Control for PMSM Drives," 2019 IEEE International Symposium on Predictive Control of Electrical Drives and Power Electronics (PRECEDE), Quanzhou, China, 2019.

[12] B. Stumberger, G. Stumberger, D. Dolinar, A. Hamler and M. Trlep, "Evaluation of saturation and cross-magnetization effects in interior permanent-magnet synchronous motor," in IEEE Transactions on Industry Applications, vol. 39, no. 5, pp. 12641271, Sept.-Oct. 2003.
[13] A. Pouramin, R. Dutta, M. F. Rahman, J. E. Fletcher and D. Xiao, "A preliminary study of the effect of saturation and crossmagnetization on the inductances of a fractional-slot concentrated-wound interior PM synchronous machine," 2015 IEEE 11th International Conference on Power Electronics and Drive Systems, Sydney, NSW, 2015, pp. 828-833.

[14] M. Caruso, A. O. Di Tommaso, R. Miceli, C. Nevoloso, C. Spataro and F. Viola, "Interior permanent magnet synchronous motors: Impact of the variability of the parameters on their efficiency," 2016 IEEE International Conference on Renewable Energy Research and Applications (ICRERA), Birmingham, 2016, pp. 1163-1167.

[15] X. Chen, J. Wang, B. Sen, P. Lazari and T. Sun, "A HighFidelity and Computationally Efficient Model for Interior Permanent-Magnet Machines Considering the Magnetic Saturation, Spatial Harmonics, and Iron Loss Effect," in IEEE Transactions on Industrial Electronics, vol. 62, no. 7, pp. 40444055, July 2015.

[16] M. Caruso, A. O. Di Tommaso, R. Miceli, C. Nevoloso, C. Spataro, F. Viola, "Characterization of the parameters of interior permanent magnet synchronous motors for a loss model algorithm", Measurement, vol. 106, pp. 196-202, August 2017.

[17] J. G. Cintron-Rivera, A. S. Babel, E. E. Montalvo-Ortiz, S. N. Foster and E. G. Strangas, "A simplified characterization method including saturation effects for permanent magnet Machines," 2012 XXth International Conference on Electrical Machines, Marseille, 2012, pp. 837-843.

[18] S. A. Odhano et al., "Parameter extraction for three phase IPM machines through simple torque tests," 2015 IEEE Energy Conversion Congress and Exposition (ECCE), Montreal, QC, 2015, pp. 1892-1898.

[19] D. E. Pinto, A. Pop, J. Kempkes and J. Gyselinck, "dq0modeling of interior permanent-magnet synchronous machines for high-fidelity model order reduction," 2017 International Conference on Optimization of Electrical and Electronic Equipment (OPTIM) \& 2017 Intl Aegean Conference on Electrical Machines and Power Electronics (ACEMP), Brasov, 2017, pp. 357-363. 